DOI:10.15740/HAS/IJAS/17.2/617-619

\title{
Estimation of irrigation water requirement of strawberry crop under polyhouse and shadenet house conditions
}

\author{
D.T. Santosh \\ Center for Smart Agriculture, Centurion University of Technology and Management, \\ Paralakhemundi (Odisha) India (Email: santosh.dt@cutm.ac.in)
}

\begin{abstract}
Strawberry is a commercial crop with high added value, which was extended to new cultivation zones of India. Therefore, it is important to know the suitability of climate condition for growing strawberry in Indian condition. Protected cultivation structures are used to cultivate crops under partial controlled climatic condition to get higher yield and better quality harvest. There are different kinds of protected cultivation structure normally adopted in India such as greenhouse, shadenet house and low tunnels. Exact of amount water and nutrients required to applied to get higher yield through minimizing loss of quality. The objective of the study is to assess the effect of protected cultivation structure on ambient temperature, relative humidity and crop water requirement of strawberry with drip irrigation system grown during winter season (November-February). Reference evapotranspiration was calculated using the FAO-56 Penman-Monteith equation considering the locally recorded weather parameters. Monthly average of daily reference evapotranspiration values are ranging between 1.3 to $3.3 \mathrm{~mm}^{-1 a y^{-1}}, 1.4$ to $3.7 \mathrm{~mm}$ day $^{-1}$ and 2.0 to $4.9 \mathrm{~mm} \mathrm{day}^{-1}$ for polyhouse, shadenet house and open field, respectively. The total water requirement of drip irrigated straw berry in protected cultivation structure is reduced by about $35.2 \%$ under polyhouse and $25.5 \%$ under shade net house in comparison to open field cultivation.
\end{abstract}

Key Words : Strawberry, Low tunnel, Shade net house, Reference evapotranspiration

View Point Article : Santosh, D.T. (2021). Estimation of irrigation water requirement of strawberry crop under polyhouse and shadenet house conditions. Internat. J. agric. Sci., 17 (2) : 617-619, DOI:10.15740/HAS/IJAS/17.2/617-619. Copyright@ 2021: Hind Agri-Horticultural Society.

Article History : Received : 25.03.2021; Revised : 05.04.2021; Accepted : 13.04.2021 